\title{
Continuous tuning of the plasmon resonance frequency of porous gold nanoparticles by mixed oxide layers
}

\author{
Laura Juhász $^{1,2} \cdot$ Bence Parditka $^{1} \cdot$ Péter Petrik $^{3} \cdot$ Csaba Cserháti $^{1}{ }^{10} \cdot$ Zoltán Erdélyi $^{1}$
}

Published online: 11 July 2020

(c) The Author(s) 2020

\begin{abstract}
Porous gold nanoparticles (PGNs) are very popular due to their high surface/volume ratio, moreover they have stronger plasmonic properties than their solid counterparts. These properties make the porous gold nanoparticles very useful for lots of applications, for instance chemical sensors, cancer therapy applications. For applications, however, it is indispensable that the resonance frequency (RF) of a plasmonic structure to be tuneable. In this work we show that the RF can be set in a wide range as desired by coating the PGNs by mixed oxide layers. By changing the composition of the coating layer, that is the mixture ratio, the RF can be shifted practically continuously in a wide range determined by the refractive index of the used oxides. As a demonstration, PGNs were coated with mixed alumina-titania oxide layers $(5-7 \mathrm{~nm})$ using plasma-enhanced atomic layer deposition method. The oxide layer, beside as a tuning tool, also stabilises the structure of the PGNs when are exposed to elevated temperature. This is shown by the influence of the temperature (from $350{ }^{\circ} \mathrm{C}$ up to $900{ }^{\circ} \mathrm{C}$ ) on the morphology, and as a consequence the optical extinction spectra, of the oxide coated PGNs.
\end{abstract}

Keywords Porous gold nanoparticle $\cdot$ Local surface plasmon resonance $\cdot$ Mixed oxide coating $\cdot$ Plasma enhanced atomic layer deposition - Tuning the plasmon resonance frequency

\section{Introduction}

Surface Plasmon (SP)[1] resonance is a collective oscillation of conduction electrons excited by the electromagnetic field of light. In the case of metallic nanoparticles (NPs), the electron oscillations induced electric field around the NP opens the possibility to manipulate visible and near infrared light on the nanoscale[1,2]. This property makes the NPs popular in a wide range of fields, including biomedical, energy, environment protection, sensing, information technology [1,3] and even in analytical applications such as surface-enhanced Raman spectroscopy (SERS) [3, 4] which is based on the phenomenon of the largely increased Raman

Csaba Cserháti

cserhati.csaba@science.unideb.hu

1 Department of Solid State Physics, Faculty of Science and Technology, University of Debrecen, P.O. Box 400, 4002 Debrecen, Hungary

2 Doctoral School of Physics, University of Debrecen, Egyetem sqr. 1, 4032 Debrecen, Hungary

3 Institute of Technical Physics and Materials Science, Centre for Energy Research, P.O.Box 49, 1525 Budapest, Hungary scattering, accomplished by placing the investigated molecules on the surface of the NPs.

Two kinds of optical excitations can occur: propagating surface plasmons and localized ones. Localized surface plasmons (LSP) are excited at metal-nanoparticle/dielectric interfaces[5, 6]. The resonance energy of these excitations are extremely sensitive to the composition, size, shape and the dielectric function of the surrounding medium of the NPs[7-16]. Modifying these parameters accordingly one may tune the optical properties of the NPs[17].

Gold and silver are the far the most investigated nanoparticle materials due to their resonances in the visible and near infrared region. There was shown[18] that the interconnected porosity inside the metallic nanoparticles offers a new opportunity to influence the resonance frequency of the NPs. Different levels of porosity, size of ligaments, interparticle distance, as well as the shape and size of the particles, provide a possibilities of surface plasmon resonance tunability[18-20].

Porous nanoparticles are promising candidates for different applications such as recoverable catalysis, drug delivery, photonic devices, nano-chemical reactors, or even in ophthalmology[21-24]. The synthesis and the formation of 
hollow nanostructures (nanospheres, nanotubes) with controlled particle and pore size, can be fabricated using a combination of solid-state dewetting and a subsequent dealloying process [25]. These porous gold nanoparticles (PGNs) have a remarkable three-dimensional structure with a high surface to volume ratio. PGNs however lose their porous morphology at relatively low temperature. In order to prevent the structure from ligament coarsening a thin oxide layer can be deposited onto the PGNs with ALD (Atomic Layer Deposition) method $[18,25]$. This succesfully hinders the degradation of nanoporous structure.

The objective of the present research is to tune the resonance energy of the PGNs by altering the dielectric function of the oxide coating. For that purpose a mixed $\mathrm{Al}_{2} \mathrm{O}_{3}-\mathrm{TiO}_{2}$ layer was deposited on the surface (also in the pores) of the NPs by plasma-enhanced atomic layer deposition (PE-ALD) method. Size, shape, composition and other parameters which might influence the optical resonances of the NPs were untouched. By changing the composition of the coating layer, that is the mixture ratio of the oxides, the resonance frequency (RF) can be shifted practically continuously. As we will see, the main advantage of this method is that no annealing is required to tune the RF (annealing is costly, can be demanding to control, etc.) and a large amount of base PGN structures can be tuned to different RF by a simple and cheap coating, which is exceptionally well controllable and reproducible. This makes the reported tuning method promising for applications.

As it was mentioned above, the main disadvantage of PGNs from an applications point of view[20] is their lack of thermal stability[20].

We expect that the mixed oxide layer, similarly to the pure one, also stabilises the structure. To check the thermal stability, the coated particles were annealed for an hour in air at different temperature from 350 to $900^{\circ} \mathrm{C}$. Morphological changes were followed by scanning electron microscopy (SEM) and optical extinction spectra were measured in a wide wavelength range.

\section{Experimental}

\subsection{Sample preparation}

PGNs were fabricated from magnetron sputtered gold and silver thin films $(6 \mathrm{~nm} / 16 \mathrm{~nm} \mathrm{Au} / \mathrm{Ag})$ by solid state dewetting/dealloying methods[25]. Thin films were deposited on $\mathrm{SiO}_{2} / \mathrm{Si}$ as well as on sapphire substrates. For the dewetting process the samples were annealed at $850{ }^{\circ} \mathrm{C}$ for half an hour in dynamic gas flow of $95 \% \mathrm{Ar}+5 \% \mathrm{H}_{2}$ mixture to prevent the oxidation of $\mathrm{Ag}$. Due to the heat treatment spherical $\mathrm{Au}-\mathrm{Ag}$ alloy nanoparticles were formed. The samples were than immersed in $65 \mathrm{wt} \%$ nitric acid for $15 \mathrm{~min}$ to etch the silver selectively from the alloy nanoparticles. According to SEM studies, the average diameter and pore size of the PGNs after the etching step was $200 \pm 50 \mathrm{~nm}$ and $10-20 \mathrm{~nm}$ respectively. Porosity of the nanoparticles was $30 \%$. The particle size and the porosity was determined by image analysis using National Instruments Vision software. After the fabrication of the PGNs the samples were coated with 5-7 nm thin mixed metal-oxide layer using PE-ALD method (Beneq TFS-200 reactor).

We produced four different types of samples which were covered by: $\mathrm{Al}_{2} \mathrm{O}_{3}$ (type 1), 35 wt. $\% \mathrm{TiO}_{2} / 65$ wt. $\% \mathrm{Al}_{2} \mathrm{O}_{3}$ (type 2), 65 wt. $\% \mathrm{TiO}_{2} / 35$ wt. $\% \mathrm{Al}_{2} \mathrm{O}_{3}$ (type 3), and $\mathrm{TiO}_{2}$ (type 4).

TMA $\left(\mathrm{Al}_{2} \mathrm{Me}_{6}\right), \mathrm{TiCl}_{4}$ and oxygen plasma were used as precursor materials. The layers were prepared at $45^{\circ} \mathrm{C}$. The chamber pressure was $7.23 \mathrm{mbar}$, while the reactor pressure was 1.186 mbar. The ALD cycle for $\mathrm{Al}_{2} \mathrm{O}_{3}$ (type 1) was $0.45 \mathrm{~s}$ TMA, $3 \mathrm{~s}$ nitrogen purge, $6 \mathrm{~s}$ oxygen plasma at $50 \mathrm{~W}$ and $3 \mathrm{~s}$ nitrogen purge. The growth rate of $\mathrm{Al}_{2} \mathrm{O}_{3}$ was $2 \AA$ /cycle, consequently 25 cycles have been applied to prepare $5 \mathrm{~nm}$ thick alumina coatings. To deposit $\mathrm{TiO}_{2}$ (type 4) the $\mathrm{TiCl}_{4}$ pulse time was $0.6 \mathrm{~s}$, which was followed by $3.5 \mathrm{~s}$ nitrogen purge, $10 \mathrm{~s}$ oxygen plasma at $50 \mathrm{~W}$ and $3.5 \mathrm{~s}$ nitrogen purge. The growth rate of the $\mathrm{TiO}_{2}$ layer was $0.7 \AA$ / cycle, accordingly 100 cycles have been applied for $7 \mathrm{~nm}$. To reach the necessary ratio in the mixed oxide covering layers (types 2 and 3) we used the ALD recipes shown in Figure 1.

\subsection{Sample characterization}

The extinction spectra were measured in the wavelength range of 300-2000 nm by SHIMADZU 3600 UV-VIS Spectrophotometer. For the optical measurements double-sided polished sapphire was used as a substrate material because of its transparency in the investigated wavelength region.

To study the thermal stability of the oxide coated PGNs, they were annealed at different temperatures from 350 to $700^{\circ} \mathrm{C}$ for an hour in ambient atmosphere. The morphology of the samples were investigated by Scanning Electron Microscope (HITACHI-S4300-CFE).

Refractive indexes of the different oxide layers were measured by ellipsometry (Woollam M-2000DI) in as deposited and in annealed state $\left(650^{\circ} \mathrm{C}\right.$ and $900^{\circ} \mathrm{C}$ for $\left.1 \mathrm{~h}\right)$. For that purpose $20 \mathrm{~nm}$ thick layers (pure and mixed) were deposited on flat Si surface.

\section{Results and discussion}

\subsection{Optical properties}

Figure 2 shows the refractive indices of the four different cover layers. The refractive indices of the mixed oxide 


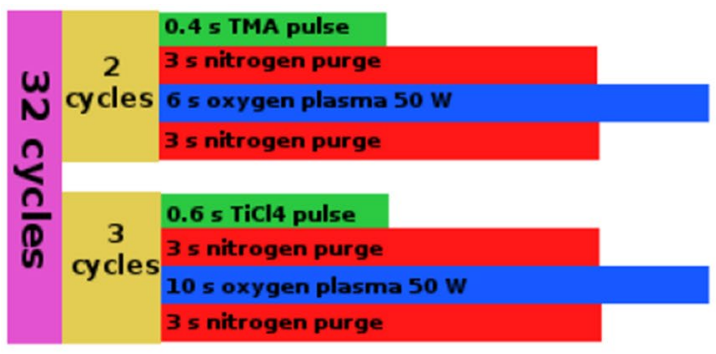

type 2

Fig. 1 ALD recipes of the mixed oxide layers

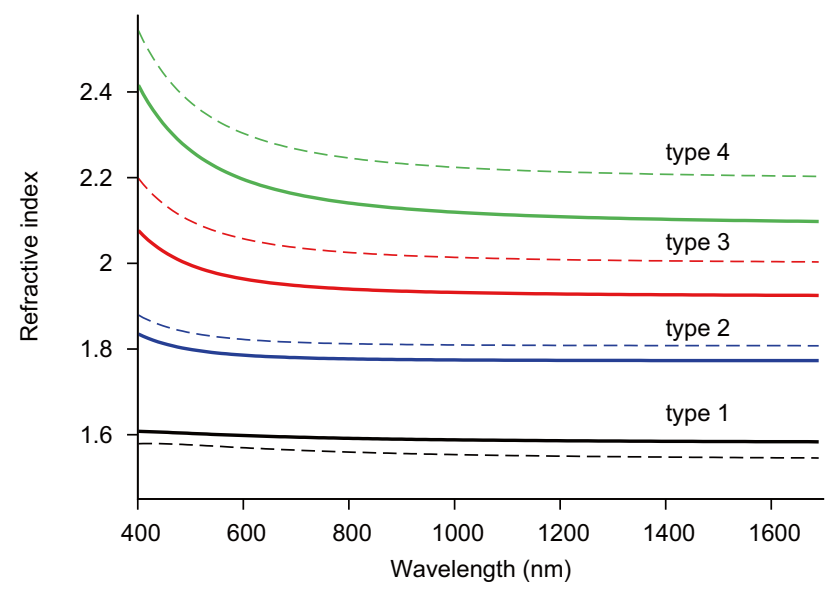

Fig. 2 Refractive indices of covering layers (solid continuous line: as prepared, dashed line: annealed)

layers (types 2 and 3 ) are between pure titania and alumina in the whole wavelength range. This points out that due to the dielectric properties the mixed oxide layers are indeed appropriate candidates to tune the local plasmon resonance properties of the individual PGNs.

As an illustration, Fig. 3 shows the extinction spectra of the uncoated PGNs and their type 2 counterparts. The most intense peak in the near-infrared region $(\approx 1200-1400 \mathrm{~nm})$ is called dipole plasmon peak. As can be clearly seen the dipole plasmon peak is shifted by about $120 \mathrm{~nm}$ due to the coating, that is $\approx 11 \%$ change to the red direction.

We determined the peak shift of the dipole plasmon peak for all different coatings. To be accurate, we repeated the experiments $4-5$ times for each type of samples. Figure 4 summarises the results we obtained; it shows the relative shift of the dipole plasmon peak as a function of the composition of the coating. As expected, the extrema of the dipole plasmon resonance peak is determined by the alumina and the titania. The position of the peak in case of mixed coatings are between the two extrema and proportional to the composition of the mixture. The difference between the extrema is $\approx 250 \mathrm{~nm}$, which means that

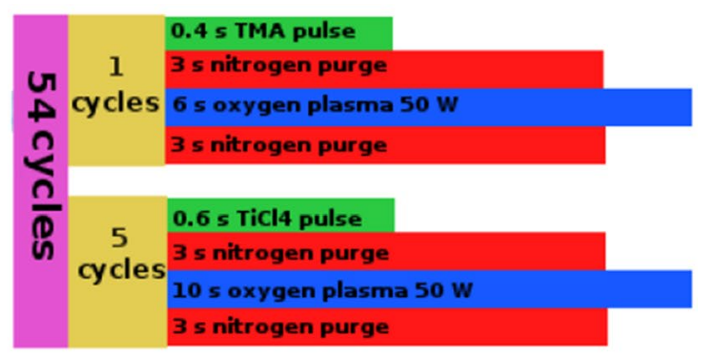

type 3

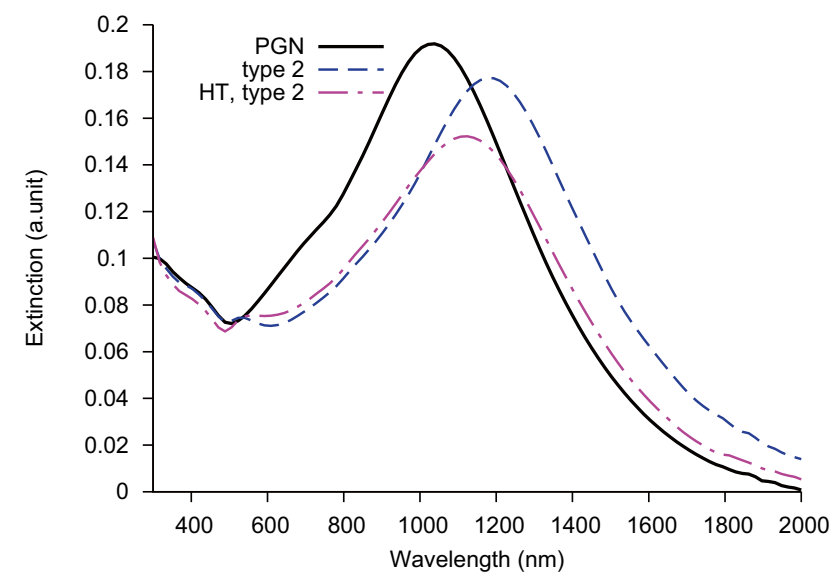

Fig. 3 Illustration of the extinction spectra of the uncoated PGNs (continuous black line), and their type 2 counterparts (dashed blue line). The coating shifts the dipole plasmon peak by about $120 \mathrm{~nm}$, that is $\sim 11 \%$ to red. The dash-dotted magenta line shows the blue shift of this later peak due to heat treatment $(\mathrm{HT})$ at $800^{\circ} \mathrm{C}$ for $30 \mathrm{~min}$. The starting size of the PGNs was $200 \pm 50 \mathrm{~nm}$

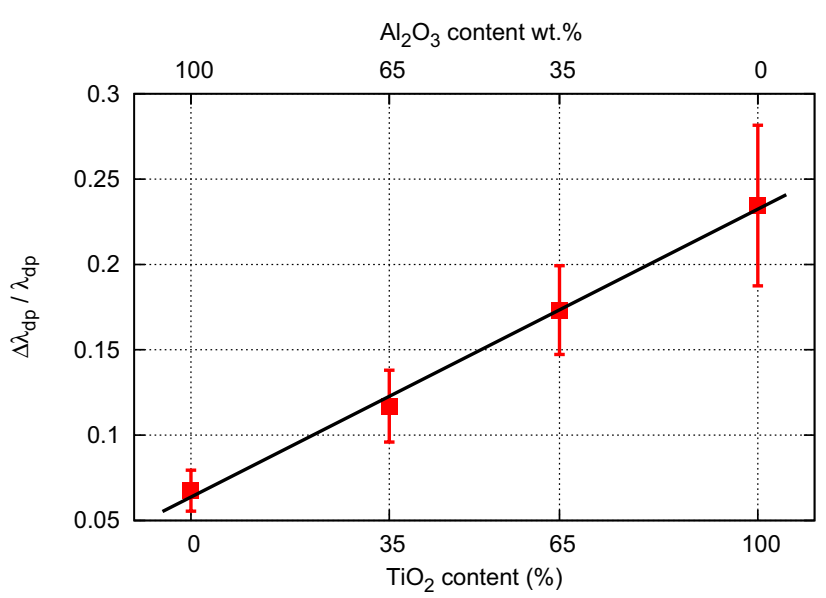

Fig. 4 Relative shift of the position of the dipole peak in case of the different coatings 
changing the alumina-titania ratio the resonance frequency of the PGNs can be controlled in this wide wavelength range. This is a huge freedom, opening many possibilities for application.

We would like to emphasise that the refractive indices of the pure oxides, which form the mixture, determine the two extrema of the relative peak shift. The coating with a mixture tunes the resonance frequency of the PGNs within this range, since it changes the local dielectric property of the particles. That is if the basic structure (size, porosity, etc.) of the PGNs is different, the positions of the extrema are also different. It means, that covering the PGNs with a mixed oxid layer the absorption wavelength can be fine tuned in another $\approx 250 \mathrm{~nm}$ range of the spectra. According to these results, there is no need to cover a wide wavelength range by continuosly adjusting the basic structure of PGNs. Only relatively large changes are required, and fine-tuning can be accomplished with a coating having a well-adjusted concentration of mixed oxides.

To illustrate this, we prepared different base structure of the PGNs. According to image analysis the particle size was $470 \pm 140 \mathrm{~nm}$, the pore and ligament size was the same as previously. As can be seen in Fig. 5, the dipole plasmon peak position of the produced PGNs is shifted red about $350 \mathrm{~nm}$ due to the larger diameter of the PGNs. Coating these PGNs with a mixed oxide layer (type 2 in Fig. 5.), the position of the dipole plasmon peak can then be fine-tuned in a different wavelength range.

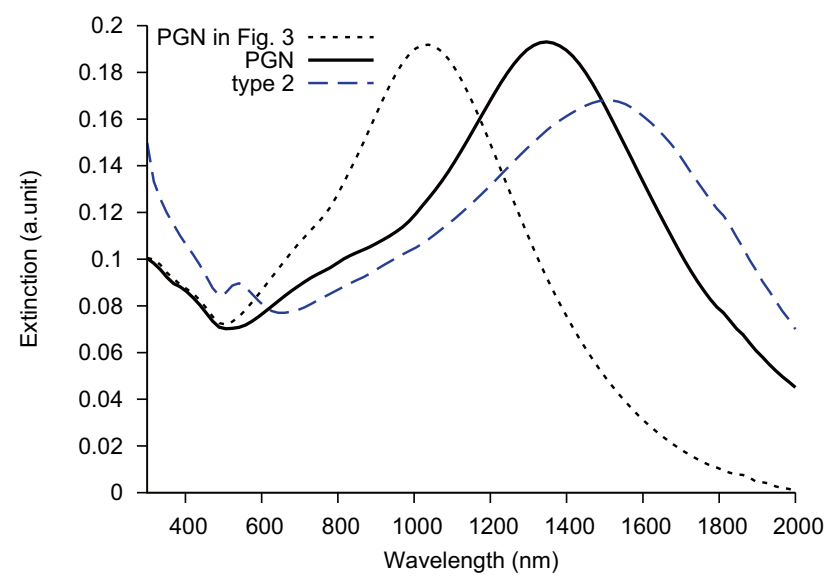

Fig. 5 Illustration of the extinction spectra of the uncoated PGNs (continuous black line), and their type 2 counterparts (dashed blue line). The size of the PGNs $(470 \pm 140 \mathrm{~nm})$ is purposefully different than in Figure 3 (dotted black line) to shift the fine tuneable range by mixed oxide coating about $350 \mathrm{~nm}$ to the red direction. The $\mathrm{Al}_{2} \mathrm{O}_{3}$ coating shifts the dipole plasmon peak by about further $150 \mathrm{~nm}$, that is $11 \%$ to the red direction

\subsection{Thermal stability}

To study the thermal stability, coated particles were annealed for an hour in an ambient atmosphere at different temperature from 350 up to $900^{\circ} \mathrm{C}$. The morphology was studied on SEM images and the optical extinction spectra were measured in a wide wavelength range.

Due to the annealing the specimens at $350{ }^{\circ} \mathrm{C}$, there was no change of the morphology in either type of metal-oxide coated PGNs. The morphology did not change until $600{ }^{\circ} \mathrm{C}$, at $650^{\circ} \mathrm{C}$, however, in the titanium-coated PGNs, the dipole plasmon peak shifted significantly toward the shorter wavelength (blue shift). In case of the pure alumina coated PGNs, neither morphological, nor optical change happened up to about $900^{\circ} \mathrm{C}$. In accordance, for the PGNs coated with the mixed layers, the peak shift takes place between these temperatures (see the dash-dotted line in Fig. 3).

There are two different components to the blue shift of the peak. The first one is related to the slight change in the refractive index of the coating due to annealing (see Fig. 2) and the second one is to the change of the morphology of the PGNs. Slow diffusion of gold starts, as a result, dark and light parts appear on the surface of PGNs. Energy dispersive X-ray spectroscopy (EDX) confirmed that dark parts do not contain any gold. (see Fig. 6).

Important to note that the higher the titania content of the coating layer, the higher the change of the refractive index due to the annealing. As can be seen in Fig. 2, the refractive index of the alumina practically does not change even after a $900{ }^{\circ} \mathrm{C}$ heat treatment, whereas that of the titania alters significantly already at $650^{\circ} \mathrm{C}$. The change of the refractive index for the mixed oxides are in between these two. The significant change with higher titania content is related to the allotrope phase transition of the titania; titania

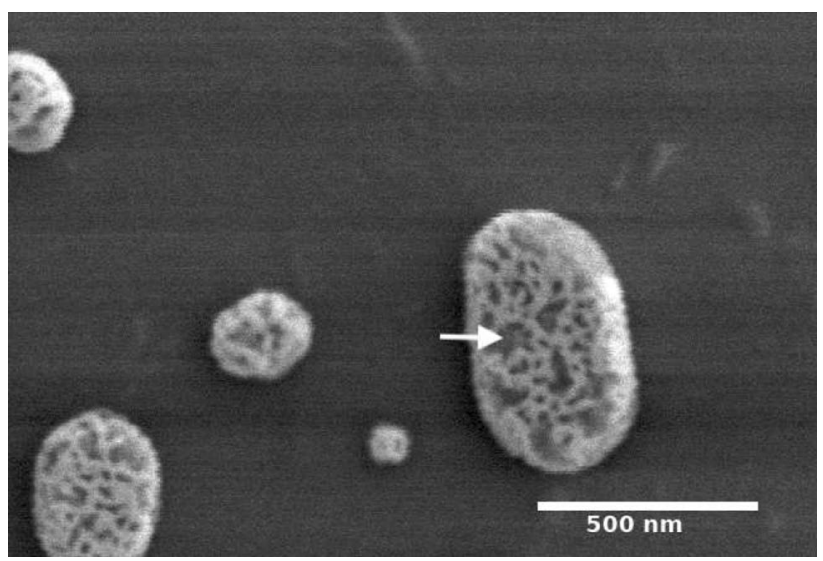

Fig. 6 SEM picture of PGNs coated by mixed metal-oxide (type 2) layer annealed at $700{ }^{\circ} \mathrm{C}$ for an hour. Coarsening of the ligament structure can be clearly seen: there is no gold in the dark regions (the white arrow points to one of such parts) 
becomes crystalline with tetragonal anatase structure at and above $650{ }^{\circ} \mathrm{C}$. It's refractive index is considerably higher than before the transition. Note that increasing the temperature further, the tetragonal rutile phase appears. Accordingly, annealing at $900^{\circ} \mathrm{C}$, we observed a further increase of the refractive index for coating types 2,3 and 4 .

\section{Conclusions}

In this work, we showed that the resonance energy of the PGNs can be continuously tuned in a simple, easily reproducible and cheap way by coating the PGNs with mixed metal-oxide layers. Very importantly this tuning can be realised without changing the base morphology of the PGNs, such as the size, the interparticle distance, pore or ligament size of the nanoparticles, which are much more difficult to plan and reproduce[19]. The extrema of the tuning range are determined by the refractive indices of the used oxides. The degree of tuning depends only on the mixing ratio of the chosen oxides. All these make this tuning method promising for applications.

As a demonstration, PGNs were coated with pure alumina, titania and various mixtures of $\mathrm{Al}_{2} \mathrm{O}_{3}-\mathrm{TiO}_{2}$ by PEALD method and their extinction spectra were measured in a wide wavelength range. The plasmonic resonance frequency of the PGNs coated with the mixed layers was indeed between, in accordance with their mixing ratio, the extrema determined by the refractive indices of alumina and titania.

We have also studied the thermal stability of the coated PGNs and found that all coatings we used increases highly the morphological stability of the PGNs. Changes of the optical properties, on one hand, can be related to the deterioration of the initial PGN structure due to surface/interface diffusion of $\mathrm{Au}$ and on the second hand to the change of the refractive index of the oxide coating due to annealing. In our case, for example, the titania transforms from an amorphous form into the crystalline anatase phase at $\sim 600-650^{\circ} \mathrm{C}$, then into rutile phase at $\sim 700^{\circ} \mathrm{C}$ inducing changes of the refractive index.

We emphasise that this tuning method is not restricted to those oxides (and even not to PGNs based plasmonic structures) we used in this work but in our opinion rather general. Different oxides and different mixing ratio can be chosen as desired for the given purpose.

Acknowledgements Open access funding provided by University of Debrecen. The work is supported by the GINOP-2.3.2-15-2016-00041 project. The project is co-financed by the European Union and the European Regional Development Fund.

\section{Compliance with ethical standards}

Conflict of interest The authors declare that they have no conflict of interest.
Open Access This article is licensed under a Creative Commons Attribution 4.0 International License, which permits use, sharing, adaptation, distribution and reproduction in any medium or format, as long as you give appropriate credit to the original author(s) and the source, provide a link to the Creative Commons licence, and indicate if changes were made. The images or other third party material in this article are included in the article's Creative Commons licence, unless indicated otherwise in a credit line to the material. If material is not included in the article's Creative Commons licence and your intended use is not permitted by statutory regulation or exceeds the permitted use, you will need to obtain permission directly from the copyright holder. To view a copy of this licence, visit http://creativecommons.org/licenses/by/4.0/.

\section{References}

1. M.A. Garcia, J. Phys. D 45(38), 389501 (2012). https://doi. org/10.1088/0022-3727/45/38/389501

2. W. Barnes, A. Dereux, T. Ebbesen, Nature 424, 824 (2003). https ://doi.org/10.1038/nature01937

3. M. Shao, K. Shoemaker, A. Peles, K. Kaneko, L. Protsailo, J. Am. Chem. Soc. 132(27), 9253 (2010). https://doi.org/10.1021/ja101 966a

4. Z. Starowicz, R. Wojnarowska-Nowak, P. Ozga, E. Sheregii, Colloid Polym. Sci. 296(6), 1029 (2018)

5. A. Baba, K. Imazu, A. Yoshida, D. Tanaka, K. Tamada, SpringerPlus 3, 284 (2014)

6. K.A. Willets, R.P. Van Duyne, Annu. Rev. Phys. Chem. 58(1), 267 (2007). https://doi.org/10.1146/annurev.physchem.58.03280 6.104607

7. T.R. Jensen, M.D. Malinsky, C.L. Haynes, R.P. Van Duyne, J. Phys. Chem. B 104(45), 10549 (2000). https://doi.org/10.1021/ jp002435e

8. K. Okamoto, B. Lin, K. Imazu, A. Yoshida, K. Toma, M. Toma, K. Tamada, Plasmonics 8, 581 (2013)

9. V.K.S. Hsiao, Y.B. Zheng, B.K. Juluri, T.J. Huang, Adv. Mater. 20(18), 3528 (2008). https://doi.org/10.1002/adma.200800045

10. P.R. Evans, G.A. Wurtz, W.R. Hendren, R. Atkinson, W. Dickson, A.V. Zayats, R.J. Pollard, Appl. Phys. Lett. 91(4), 043101 (2007). https://doi.org/10.1063/1.2759463

11. Y.R. Leroux, J.C. Lacroix, K.I. Chane-Ching, C. Fave, N. Félidj, G. Lévi, J. Aubard, J.R. Krenn, A. Hohenau, J. Am. Chem. Soc. 127(46), 16022 (2005). https://doi.org/10.1021/ja054915v

12. Y. Leroux, J.C. Lacroix, C. Fave, G. Trippe, N. Félidj, J. Aubard, A. Hohenau, J.R. Krenn, ACS Nano 2(4), 728 (2008). https://doi. org/10.1021/nn700438a

13. Y. Leroux, J.C. Lacroix, C. Fave, V. Stockhausen, N. Félidj, J. Grand, A. Hohenau, J.R. Krenn, Nano Lett. 9(5), 2144 (2009). https://doi.org/10.1021/n1900695j

14. J. Dintinger, S. Klein, T. Ebbesen, Adv. Mater. 18(10), 1267 (2006). https://doi.org/10.1002/adma.200502393

15. V. Stockhausen, P. Martin, J. Ghilane, Y. Leroux, H. Randriamahazaka, J. Grand, N. Felidj, J.C. Lacroix, J. Am. Chem. Soc. 132(30), 10224 (2010). https://doi.org/10.1021/ja103337d

16. A. Yoshida, K. Imazu, X. Li, K. Okamoto, K. Tamada, Langmuir 28(49), 17153 (2012). https://doi.org/10.1021/la303533f

17. M. Kjeldsen, J. Hansen, T. Pedersen, P. Gaiduk, A. Larsen, Appl. Phys. A 100(1), 31 (2010)

18. A. Kosinova, D. Wang, E. Baradács, B. Parditka, T. Kups, L. Klinger, Z. Erdélyi, P. Schaaf, E. Rabkin, Acta Mater. 127, 108 (2017). https://doi.org/10.1016/j.actamat.2017.01.014

19. P. Olk, J. Renger, M.T. Wenzel, L.M. Eng, Nano Lett. 8(4), 1174 (2008) 
20. A. Chen, S. Shi, Y. Qiu, X. Xie, H. Ruan, J. Gu, D. Pan, Microporous Mesoporous Mater. 202, 50 (2015). https://doi.org/10.1016/j. micromeso.2014.09.048

21. K.L. Kelly, E. Coronado, L.L. Zhao, G.C. Schatz, J. Phys. Chem. B 107(3), 668 (2003)

22. P.K. Jain, K.S. Lee, I.H. El-Sayed, M.A. El-Sayed, J. Phys. Chem. B 110(14), 7238 (2006)

23. C.L. Haynes, R.P.V. Duyne, Nanosphere lithography. J. Phys. Chem. B 105(24), 5599 (2001)

24. J. Wu, G. Yue, J.L.Y. Xiao, M. Huang, Q.T.Z. Lan, Y. Huang, L. Fan, S. Yin, T. Sato, Sci. Rep. 3, 1283 (2013)
25. A. Kosinova, D. Wang, P. Schaaf, O. Kovalenko, L. Klinger, E. Rabkin, Acta Mater. 102, 108 (2016). https://doi.org/10.1016/j. actamat.2015.09.024

Publisher's Note Springer Nature remains neutral with regard to jurisdictional claims in published maps and institutional affiliations. 